\title{
JUURNAL.RU
}

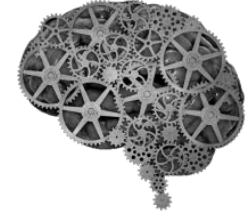

COMPANY GROUP "INTELLEKT"

Колесников В.Н., Фомичева Е.В. Ростовский государственный медииинский университет Ростов-на-Дону, Россия

doi: 10.18411/lj2016-3-17

\section{Использование передней активной риноманометрии для диагностики вазомоторного ринита}

Риноманометрия (РММ) - наиболее распространенный метод оценки дыхательной функции носа [1]. Он широко применяется для изучения различных заболеваний носа и околоносовых пазух, сопровождающихся нарушением носового дыхания [2, 3, 4, 5].

Чувствительность метода ПАРМ достаточно высока, что подтверждается его успешным применением для оценки провокационных назальных проб у больных аллергическим ринитом [6].

Однако для результатов ПАРМ характерен большой разброс как при исследовании в популяции, так и для отдельного индивида при многократном исследовании, что отчетливо показано в работе В.С.Козлова и соавт. [7]. Последнее обстоятельство обусловлено наличием носового цикла.

Исходя из вышеизложенного, повышение практической значимости метода ПАРМ может быть достигнуто такой модификацией его проведения, которая позволит свести к минимуму влияние носового цикла, а также избежать необходимости сопоставления полученных результатов со среднестатистическими значениями.

Наиболее просто эти условия реализуются с помощью функциональных тестов, предусматривающих сравнение исходных и конечных результатов 
исследования каждого больного.

Целью исследования было изучение изменений носовой резистентности у больных вазомоторным ринитом.

Исследование дыхательной функции носа 42 больным с вазомоторным ринитом в возрасте от 18 до 35 лет проводилось с помощью риноманометра RHINOMANOMETER 200 фирмы «ATMOS». Контрольную группу составили 30 человек той же возрастной группы, не страдающих заболеваниями носа и околоносовых пазух. Перед исследованием исключались физические и эмоциональные нагрузки, вливание в нос сосудосуживающих капель. ПАРМ выполняли до и после функциональной пробы - стандартного тредмил - теста на беговой дорожке, скорость движения и наклон которой определяли по протоколу Брюса в зависимости от возраста, роста и веса больного. Анализировали значения суммарного объемного потока (СОП) и суммарного сопротивления (СС) в точке фиксированного давления 150 Паскаль (Рa). Результаты функциональной пробы оценивали по изменению этих показателей до и после физической нагрузки.

При анализе полученных данных установлено, что исходные значения СС у больных с вазомоторным ринитом превышают таковые у здоровых лиц, однако эта разница статистически не достоверна $(\mathrm{p}>0,05)$. СОП у больных с вазомоторным ринитом ниже, чем в контрольной группе, однако и эти цифры не имеют достоверных различий $(p>0,05)$. Направленность изменений этих показателей после ФН в обеих исследуемых группах однотипна. Таким образом, сравнение абсолютных показателей ПАРМ у больных с вазомоторным ринитом и здоровых лиц не выявляет диагностически значимых различий.

Анализ относительных показателей позволил преодолеть влияние большого разброса данных на проявление основных закономерностей реакции носовой резистентности на физическую нагрузку. Мы высчитали изменения анализируемых показателей после ФН у каждого исследованного в процентах по отношению к исходному уровню, а затем полученные относительные величины 
обработали методами вариационной статистики.

Относительные показатели СС выявляют его достоверное уменьшение после $Ф Н$ у больных с вазомоторным ринитом по сравнению с контрольной группой $(49,09 \pm 5,31 \%$ и $31,11 \pm 5,35 \%$ соответственно, $\mathrm{t}=2,38, \mathrm{p}<0,05)$. Увеличение СОП после $Ф Н$ у больных с вазомоторным ринитом на 106,87 \pm $16,05 \%$ также достоверно превышает возрастание этого показателя в контрольной группе - на 49,86 $\pm 13,06 \%(\mathrm{t}=2,75, \mathrm{p}<0,05)$.

Таким образом, сопоставление относительных показателей ПАРМ демонстрирует наличие повышенной реактивности слизистой оболочки носа у больных с вазомоторным ринитом по сравнению с контрольной группой.

Известно, что носовая резистентность зависит, в основном, от кровенаполнения емкостных сосудов (венул) слизистой оболочки полости носа и реагирует на действие различных физиологических стимулов, таких как температура, гипервентиляция, физические упражнения, постуральные изменения. Физическая нагрузка уменьшает носовую резистентность путем редукции кровенаполнения емкостных (венозных) сосудов.

Вазомоторный ринит протекает на фоне общей и местной вегетативной дисфункции, проявляющейся вазомоторной дистонией. $\mathrm{y}$ больных $\mathrm{c}$ вазомоторным ринитом отмечается повышенная лабильность вегетативных функций, вследствие чего ответ на действие различных, в том числе, неспецифических раздражителей может резко отличаться от нормы. Это объясняет выявленные нами различия изменений суммарного носового сопротивления в ответ на физическую нагрузку у больных с вазомоторным ринитом и у здоровых испытуемых.

\section{Выводы.}

1. Диагностические возможности ПАРМ могут быть расширены применением функциональных проб, оказывающих влияние на носовую резистентность. 
2. Функциональная проба дает возможность анализировать динамику изменения носовой резистентности за короткий временной промежуток, что позволяет минимизировать влияние носового цикла на результаты исследования.

3. Функциональная проба позволяет провести сопоставление относительных показателей, характеризующих динамику отдельных параметров ПАРМ, что уменьшает влияние индивидуальных различий их исходных значений. Проба с физической нагрузкой позволяет выявить повышенную реактивность сосудистой системы полости носа, характерную для вазомоторного ринита, что может быть использовано для дифференциальной диагностики данного заболевания. 


\section{Литература:}

1. Бойко Н.В., Колесников В.Н. Клиническая ценность передней активной риноманометрии. Российская ринология. 2006. № 3. С. 4-7.

2. Русецкий Ю.Ю., Чернышенко И.О., Попов М.А., Иванов С.Л., Мирошниченко А.П. Состояние дыхательной функции носа при свежих травмах по данным передней активной риноманометрии. Вестник оторинолар. 2007. № 5. С. 29-33.

3. Русецкий Ю.Ю., Соболев В.П., Карапетян Л.С. Объективизация специфических проб для выявления дисфункции носового клапана. Рос. оторинолар. 2014. Т. 72. № 5. С. 57-64.

4. Бойко Н.В., Колесников В.Н. Значение передней активной риноманометрии для диагностики атрофического ринита. Рос. ринология. 2014. T. 22. № 2. C. 32-33.

5. Бойко Н.В., Писаренко Е.А., Морозова Е.Е., Вербицкая Л.П., Колесников В.Н. Диагностика и лечение одонтогенного синусита . Российская ринология. 2009. Т. 17. № 3. С. 6-10.

6. Schwetz S., Olze H., Melchisedech S. et al. Efficacy of pollen blocker cream in the treatment of allergic rhinitis. Arch. Otolaryngol. Head Neck Surg. 2004. - Vol. 130, № 8. - P. 979-984.

7. Козлов В.С., Державина Л.Л., Шиленкова В.В. Акустическая ринометрия и передняя активная риноманометрия в исследовании носового цикла. Рос. ринология. - 2002. - № 1. - С. 4-10. 